\title{
Epidemiological evaluation of YAG capsulotomy incidence for posterior capsule opacification in various intraocular lenses in Japanese eyes
}

This article was published in the following Dove Press journal:

Clinical Ophthalmology

I September 2015

Number of times this article has been viewed

\author{
Yutaro Nishi ${ }^{1,2}$ \\ Tomohiro Ikeda' \\ Kayo Nishi \\ Osamu Mimura' \\ 'Department of Ophthalmology, \\ Hyogo College of Medicine, Hyogo, \\ ${ }^{2}$ Nishi Eye Hospital, Osaka, Japan
}

Correspondence: Yutaro Nishi Department of Ophthalmology, Night Graduate School, Hyogo College of Medicine, I-I, Mukogawa-chou, Nishinomiya, Hyogo 663-850I, Japan $\mathrm{Tel}+8 \mathrm{I} 798456270$

Fax +8I 798456937

Email y.nishi@nishi-ganka.or.jp
Background and objective: We investigated the yttrium aluminum garnet (YAG) capsulotomy rates in various intraocular lenses (IOLs).

Study design/patients and methods: We retrospectively analyzed 23,440 eyes implanted with either MA60BM, MA60AC, VA-60BB, CeeOnEdge, Clariflex, Technis Z9002, SI-40NB, or UV26T IOLs. We calculated the YAG capsulotomy rates at 1, 3, 5, and 10 years post lens implantation.

Results: YAG capsulotomy rates at 3 years postimplantation for the eight groups of IOLs were, respectively, 3.7\%, 3.9\%, 23.7\%, 3.4\%, 4.5\%, 4.7\%, 10.4\%, and 21.0\%. YAG capsulotomy rates at 10 years postimplantation for the MA60BM and SI-40NB IOLs were, respectively, $9.1 \%$ and $15 \%(P<0.05)$. The average YAG rates for all sharp-edged and round-edged IOLs at 5 years postimplantation were, respectively, $5.2 \% \pm 0.7 \%$ and $25.6 \% \pm 9.0 \%(P<0.05)$.

Conclusion: In all studied IOLs, posterior capsule opacification prevention seemed to be associated with the posterior optic sharp-edge design. Round-edged silicone IOLs may also retard posterior capsule opacification formation, though not as much as sharp-edged IOLs. As the follow-up period progressed, round-edged silicone IOLs showed significantly higher YAG rates than sharp-edged IOLs.

Keywords: silicone, intraocular lenses, sharp optic edge, chi-square test, implantation surgery, posterior capsule opacification

\section{Introduction}

The rate of postoperative posterior capsule opacification (PCO) following cataract surgery has been a subject of many reports. The rate of yttrium aluminum garnet (YAG) capsulotomy for PCO with respect to the design and material composition of intraocular lenses (IOLs) has been investigated. Comparisons between IOLs, with and without a sharp-edged optic, ${ }^{1-4} 1$-piece IOLs, and 3-piece IOLs, ${ }^{5-7}$ have been made. IOL materials have long been considered to be a factor in PCO formation. ${ }^{8-11}$ Especially, the silicone IOLs have been of interest in this regard. ${ }^{3,12,13}$ YAG capsulotomy to treat $\mathrm{PCO}^{14}$ has been a mainstay of therapy. At the same time, it has led investigators assessing methods for the prevention of PCO formation to consider the design of and the material used for IOLs, particularly in relation to capsular bending. ${ }^{15-17}$ PMMA (poly(methyl methacrylate)) without a sharp-edged optics, for example, was found to permit rapid proliferation of lens epithelial cells (LECs) with a resultant severe PCO, whereas the posterior optic sharp-edge design was noted to prevent LECs from proliferating, regardless of the material used in the IOL. ${ }^{15,17}$

However, interestingly, in a long-term follow-up, a sharp optic edge design that did not result in diminution of PCO was reported with the use of hydrophobic acrylic 
IOLs when compared with silicone IOLs without a sharpedged optic. ${ }^{12,18}$ Further studies of silicone IOLs in this regard would be useful.

We retrospectively investigated Japanese eyes, at our institution that underwent cataract surgery and YAG capsulotomy over a 17-year period. YAG rates in IOLs of different designs and materials were determined at 1,3, and 5 years and, in the case of the MA60BM and SI-40NB IOLs, at 10 years postsurgery. Then, the average YAG rates of all sharp-edged IOLs were compared with those of round-edged IOLs.

\section{Patients, materials and methods Types of IOLs}

A retrospective review of all patient eyes was undertaken, which underwent uneventful phacoemulsification and aspiration with an implantation of IOLs between January 1, 1997 and June 30, 2014 at Nishi Eye Hospital, Osaka, Japan, utilizing an electronic chart system (Topcon, Tokyo, Japan). Various IOLs implanted in minimum of 400 eyes during this period were screened. As a result, eight groups of IOLs were selected. The Nishi Eye Hospital Ethics Review Committee approved the study.

The eight groups of IOLs investigated in this study were as follows: MA60BM (3-piece hydrophobic IOL with a sharp optic edge), MA60AC (3-piece hydrophobic IOL with a sharp optic edge), VA-60BB (1-piece hydrophobic IOL with an incomplete sharp optic edge), CeeOnEdge (3-piece silicone IOL with a sharp optic edge), Clariflex (3-piece silicone IOL with a sharp optic edge), Technis Z9002 (3-piece silicone IOL with a sharp optic edge), SI-40NB (3-piece silicone IOL without a sharp optic edge), and UV26T (3-piece PMMA IOL without a sharp optic edge). The posterior optic edge of VA-60BB is described here as "incomplete sharp optic edge", meaning the edge is not sharp enough. When the posterior optic edge is sharp but not clinically sharp enough at a micro level for PCO prevention, ${ }^{19,20}$ it may be described as "incomplete sharp optic edge".
The details for each IOL in the eight groups are found in Table 1.

\section{Surgery and YAG capsulotomy}

The standard phacoemulsification and aspiration with an implantation of an IOL were performed in all cases.

Several surgeons were involved, and all surgeries were performed at Nishi Eye Hospital under the supervision of one experienced surgeon (ON).

YAG capsulotomy was also performed at the same hospital when clinical PCO was noted in the $3 \mathrm{~mm}$ central area of the IOL optic and when the patient subjectively presented with decreased vision with best-corrected visual acuity of 20/40 or worse. The morphological evaluation of PCO was not possible. The study adhered to Helsinki Accords.

\section{Exclusion criteria}

Exclusion criteria included ocular diseases such as active keratitis, uncontrolled glaucoma, uveitis, and conditions that would complicate a surgical intervention, such as an opacified cornea or severe pterygium. Cases of posterior capsule rupture during surgery were also excluded, though eyes with pseudoexfoliation syndrome and diabetics were not. Dropping out of the assessment during the follow-up was unclear and not excluded.

\section{Statistical analysis}

Statistical analysis of YAG rates using Pearson's chi-square test was done, and $P<0.05$ was considered to be statistically significant.

The average YAG rates for all sharp-edged (MA60BM, MA60AC, CeeOnEdge, Clariflex, and Technis Z9002) and round-edged (VA-60BB, SI-40NB, and UV26T) IOLs were also analyzed using Welch's $t$-test, and $P<0.05$ was considered to be statistically significant.

Table I The manufacturer, material, optic diameter $(\mathrm{mm})$, IOL design, and haptic angulation $\left(^{\circ}\right)$ of each $\mathrm{IOL}$

\begin{tabular}{|c|c|c|c|c|c|c|}
\hline IOL & Manufacturer & Material & $\begin{array}{l}\text { Optic diameter } \\
(\mathrm{mm})\end{array}$ & $\begin{array}{l}\text { Posterior optic edge } \\
\text { characteristic }\end{array}$ & $\begin{array}{l}\text { I- or } \\
\text { 3-piece }\end{array}$ & $\begin{array}{l}\text { Haptic } \\
\text { angulation }\left({ }^{\circ}\right)\end{array}$ \\
\hline MA60BM & Alcon (Fort Worth, TX, USA) & Hydrophobic acrylic & 6.0 & Sharp & 3-piece & 10 \\
\hline MA60AC & Alcon (Fort Worth, TX, USA) & Hydrophobic acrylic & 6.0 & Sharp & 3-piece & 10 \\
\hline VA-60BB & Hoya (Tokyo, Japan) & Hydrophobic acrylic & 6.0 & Incomplete & I-piece & 5 \\
\hline CeeOnEdge & Pharmacia (Uppsala, Sweden) & Silicone & 6.0 & Sharp & 3-piece & 6 \\
\hline Clariflex & AMO (Santa Ana, CA, USA) & Silicone & 6.0 & Sharp & 3-piece & 10 \\
\hline Technis Z9002 & AMO (Santa Ana, CA, USA) & Silicone & 6.0 & Sharp & 3-piece & 10 \\
\hline SI-40NB & AMO (Santa Ana, CA, USA) & Silicone & 6.0 & Round & 3-piece & 10 \\
\hline UV26T & Menicon (Nagoya, Japan) & PMMA & 6.0 & Round & 3-piece & 10 \\
\hline
\end{tabular}

Abbreviations: IOL, intraocular lens; PMMA, poly(methyl methacrylate). 


\section{Results \\ Overall YAG rates}

Between January 1, 1997 and June 30, 2014, a total of 23,440 eyes were implanted, and these were divided into the eight groups of IOLs for analysis as follows: group 1: MA60BM (5,007 eyes), group 2: MA60AC (421 eyes), group 3: VA-60BB (1,606 eyes), group 4: CeeOnEdge (1,601 eyes), group 5: Clariflex $(2,861$ eyes), group 6: Technis Z9002 (6,495 eyes), group 7: SI-40NB (3,184 eyes), and group 8: UV26T ( 2,265 eyes).

The overall YAG rates, the mean, the maximum, and the minimum period from IOL implantation to YAG capsulotomy in each IOL group, and the mean patient age at time of surgery are found in Table 2.

\section{YAG rates at each visit}

Table 3 describes the YAG rates for each IOL group at 1, 3, 5 , and 10 years post implantation surgery (for $P$-values, see "Notes:"). The 5-year YAG rates of Technis Z9002 were not available. The 10-year YAG rates were available for two groups of IOLs, MA60BM and SI-40NB.

VA-60BB (1-piece hydrophobic IOL with an incomplete sharp edge) and UV26T (3-piece PMMA IOL without a sharp edge) showed the highest YAG rates throughout the follow-up period.

At 1, 3, and 5 years postimplantation, all sharp-edged (MA60BM, MA60AC, CeeOnEdge, Clariflex, and Technis Z9002) IOLs showed a similar performance in general.

SI-40NB with a round edge had higher YAG rates compared to the sharp-edged (MA60BM, MA60AC, CeeOnEdge, Clariflex, and Technis Z9002) IOLs, but lower YAG rates than VA60BB and UV26T.

\section{Statistical analysis of average YAG rates}

Table 4 describes the average YAG rates for the sharp-edged group (MA60BM, MA60AC, CeeOnEdge, Clariflex, and
Technis Z9002) and the round-edged group (VA-60BB, SI-40NB, and UV26T) at 1, 3, and 5 years post lens implantation surgery.

\section{Discussion}

The design and material used for IOLs influenced clinical PCO formation and the need for YAG capsulotomy. During the early postoperative period, only a few cases in each IOL group, each meeting the criteria of YAG capsulotomy, underwent YAG capsulotomy, and this early postoperative data were included in the analysis.

This large sample retrospective study showed that silicone IOLs with a sharp edge compared to hydrophobic acrylic IOLs with a sharp edge had a similar or slightly better capability to prevent $\mathrm{PCO}^{1,2,8,13}$ when the YAG rates are taken into consideration. The sharp-edged (MA60BM, MA60AC, CeeOnEdge, Clariflex, and Technis Z9002) IOLs showed significantly lower YAG rates on average than the roundedged (VA-60BB, SI-40NB, and UV26T) IOLs $(P<0.05)$, emphasizing the importance of the role of posterior optic sharp-edge design for PCO prevention. ${ }^{1,3,7,15,17}$

The hydrophobic IOL with an incomplete sharp-edged optic (VA-60BB) and the PMMA IOL without a sharp-edged optic (UV26T) had the highest YAG rates. The silicone IOL without a sharp-edged optic (SI-40NB) had lower YAG rates than did the latter two IOLs, and the difference was statistically significant $(P<0.05)$. The reason for this finding deserves future investigation.

Silicone IOLs may have the tendency to induce more stable capsular bending formation that, together with anterior fibrosis formation, may play a role in the prevention of PCO. The posterior optic edge design can vary with each manufacture. A sharp-edged optic with one design may have characteristics more in keeping with a round-edged optic design. ${ }^{19}$ Even among the same type of IOLs, if the IOL

Table 2 The overall YAG rates (\%), age at the time of surgery (years), mean, maximum, and minimum period (months) from IOL implantation to YAG capsulotomy in each IOL group

\begin{tabular}{|c|c|c|c|c|c|c|}
\hline Age (years) & IOL & Total (eyes) & YAG (eyes) & YAG rates (\%) & Period (months) & Period (min/max) \\
\hline $65 \pm 11.9$ & MA60BM & 5,007 & 501 & 10.0 & $56 \pm 41$ & $1 / 176$ \\
\hline $66 \pm 9.4$ & MA60AC & 421 & 28 & 6.7 & $38 \pm 34$ & $1 / 122$ \\
\hline $66 \pm 9.2$ & VA-60BB & 1,606 & 429 & 26.7 & $25 \pm 16$ & $\mathrm{I} / 88$ \\
\hline $71 \pm 9.6$ & CeeOnEdge & $|, 60|$ & 86 & 5.4 & $34 \pm 22$ & $1 / 98$ \\
\hline $71 \pm 9.1$ & Clariflex & $2,86 I$ & 164 & 5.7 & $22 \pm 19$ & $1 / 100$ \\
\hline $72 \pm 9.0$ & Technis Z9002 & 6,495 & 303 & 4.7 & $10 \pm 10$ & $1 / 50$ \\
\hline $68 \pm 10.7$ & SI-40NB & 3,184 & 500 & 15.7 & $32 \pm 28$ & $\mathrm{I} / \mathrm{I} 46$ \\
\hline $7 I \pm 10.1$ & UV26T & 2,265 & 642 & 28.3 & $27 \pm 20$ & $\mathrm{I} / \mathrm{I} 27$ \\
\hline
\end{tabular}

Abbreviations: IOL, intraocular lens; YAG, yttrium aluminum garnet; min, minimum; max, maximum. 
Table 3 The YAG rates (\%) in each IOL group during the early (I year), middle ( 3 years), long-term ( 5 and 10 years) postoperative period

\begin{tabular}{lllll}
\hline IOL & I year & $\mathbf{3}$ years & $\mathbf{5}$ years & I 0 years \\
\hline MA60BM & 1.3 & 3.7 & 6.1 & 9.1 \\
MA60AC & 1.7 & 3.9 & 5.1 & - \\
VA-60BB & 5.7 & 23.7 & 31.2 & - \\
CeeOnEdge & 0.9 & 3.4 & 4.4 & - \\
Clariflex & 1.8 & 4.5 & 5.3 & - \\
Technis Z9002 & 3.1 & 4.7 & - & - \\
SI-40NB & 3.5 & 10.4 & 13.6 & 14.9 \\
UV26T & 5.2 & 21.0 & 25.9 & - \\
\hline
\end{tabular}

Notes: The difference of the YAG rates between VA-60BB and UV26T and the other IOLs with a sharp edge (MA60BM, MA60AC, CeeOnEdge, Clariflex, and Technis Z9002) was statistically significant throughout the follow-up period $(P<0.05)$. At $I, 3$, and 5 years postimplantation, there was no statistically significant difference between the two IOLs (MA60BM and MA60AC) and silicone IOLs with a sharp edge (CeeOnEdge, Clariflex, and Technis Z9002), with exceptions at the I- and 3-year follow-up period between MA60BM and Technis Z9002 $(P<0.05)$ as well as at the 5 -year follow-up period between MA60BM and CeeOnEdge $(P<0.05)$. SI-40NB had higher YAG rates compared to the sharp-edged IOLs, but lower rates than VA-60BB and UV26T. At I, 3, and 5 years follow-up, the difference between SI-40NB and the sharp-edged IOLs (MA60BM, MA60AC, CeeOnEdge, Clariflex, and Technis Z9002) as well as between SI-40NB, VA-60BB, and UV26T was statistically significant $(P<0.05)$, with the only exception that the difference between $\mathrm{SI}-40 \mathrm{NB}$ and Technis $Z 9002$ at the I-year follow-up was not statistically significant $(P=0.3 \mathrm{I})$. At the I0-year follow-up, the YAG rates of SI-40NB were significantly higher than those of MA60BB $(P<0.05)$.

Abbreviations: IOL, intraocular lens; YAG, yttrium aluminum garnet.

power is different, the sharpness index reported is different. ${ }^{20}$ The potential importance of the sharpness and thickness of the posterior optic edge was emphasized while investigating commercially available IOLs. ${ }^{19}$ Since capsular bending formation is a key factor in PCO prevention, the sharpness of the posterior optic edge and the characteristics of materials upon which this bending is dependent are important.

Should the formation of capsular bending at an early stage be inhibited in any model of IOL, PCO development would occur. ${ }^{15,17}$ LECs stop proliferating, when their contact is inhibited at capsular bending and when they are in $\mathrm{G}_{0}$ phase of the cell cycle. ${ }^{17}$ Whether the LECs which once stopped proliferating can be reactivated or not is a subject for further investigation.

A previous morphological study in Europe reported that silicone IOLs with a round edge had less PCO in the long run than hydrophobic acrylic IOLs with a sharp edge. ${ }^{12}$ In this

Table 4 The average YAG rates (\%) for the sharp-edged group and the round-edged group at I, 3, and 5 years post lens implantation surgery

\begin{tabular}{llll}
\hline Group & I year & 3 years & $\mathbf{5}$ years \\
\hline Sharp edged & $1.7 \pm 0.8$ & $4.0 \pm 0.5$ & $5.2 \pm 0.7$ \\
Round edged & $4.8 \pm 1.2$ & $18.4 \pm 7.0$ & $25.6 \pm 9.0$ \\
\hline
\end{tabular}

Notes: The sharp-edged group showed significantly lower YAG rates on average than the round-edged group at I, 3, and 5 years post lens implantation surgery $(P<0.05)$.

Abbreviation: YAG, yttrium aluminum garnet. study, in Japanese eyes, silicone IOLs with a round edge had higher YAG rates than hydrophobic acrylic IOLs with a sharp edge, and the difference was statistically significant $(P<0.05)$. Silicone IOLs appeared to have a quite similar capability $^{1,2,8}$ to prevent PCO formation when compared with hydrophobic acrylic IOLs, as long as the posterior optic edge was sharp. A round-edged silicone IOL likewise had the effect of $\mathrm{PCO}$ prevention, ${ }^{2}$ though less than all categories of sharp-edged IOLs $(P<0.05)$.

Though statistical significance was achieved between SI-40NB and MA60BM, clinically the difference of YAG rates was not very apparent. This may have to do with the duration of the follow-up period, the sample size, the sharpness index of each IOL, the overlapping area between an IOL and anterior capsule, the haptic design, ${ }^{21}$ and the study design. A recent report showed that indeed the silicone IOL with a round edge was as good as the acrylic IOL with a sharp edge in the prevention of PCO during the long-term follow-up. ${ }^{18}$

The limitations of our study include the surgical technique of several surgeons, the ocular axial length, the sharpness index of the optic edge, and haptic angulation, ${ }^{21}$ all of which can influence PCO development and affect the final results. Absence of data for the overlapping area between the anterior capsule and IOL may be another limitation. Also, the severity of PCO was not objectively quantified when YAG capsulotomy was performed. We could not accurately assess the number of cases in each of the eight IOL groups that dropped out of the study. Consequently, Kaplan-Meier survival curves for each IOL were not available. Instead, Welch's $t$-test was used for the statistical analysis of the average YAG rates of all sharp-edged (MA60BM, MA60AC, CeeOnEdge, Clariflex, and Technis Z9002) and round-edged (VA-60BB, SI-40NB, and UV26T) IOLs. Since the YAG rates in this study were low, they may be underestimated due to undercounted cases that dropped out in the course of the later examinations.

The large sample size of this intrainstitutional epidemiological study, however, militates against these restrictions, though a multicenter prospective morphological study with a large sample size would add to the validity of the findings.

While randomized prospective clinical trials may provide more accurate data, they may also be biased, particularly because of their limited sample size. Retrospective studies may be useful for epidemiological screening of data based on the large sample size, although the data obtained may be less accurate. Nevertheless, the retrospective nature of this study of comparative YAG rates in IOLs would provide a certain epidemiological evidence for the clinical PCO development in various IOLs in Japanese eyes. 
In conclusion, $\mathrm{PCO}$ formation and the timing for YAG capsulotomy varied with the IOLs employed. In IOL groups made of silicone, hydrophobic acrylic, and PMMA, the role of a posterior optic sharp-edge design seemed to be critical for clinical PCO prevention, judging from the YAG rates. A silicone IOL showed a similar performance in clinical PCO prevention when compared to a hydrophobic acrylic IOL, as long as the optic edge was sharp. A round-edged silicone IOL may also retard clinical PCO formation, though not to the same degree as a sharp-edged IOL. As the follow-up period progressed, silicone IOLs with a round-edged optic showed significantly higher YAG rates than did sharp-edged IOLs, although clinically the disparity was slight. More clinical and laboratory studies of the performance of silicone IOLs are desired.

Last but not least, longer term follow-up with IOLs of different designs and materials with a large sample size, preferably, a multicenter prospective morphological study, is definitely required for further investigation.

\section{Disclosure}

The authors report no conflicts of interest in this work.

\section{References}

1. Auffarth GU, Golescu A, Becker KA, Völcker HE. Quantification of posterior capsule opacification with round and sharp edge intraocular lenses. Ophthalmology. 2003;110:772-780.

2. Mester U, Fabian E, Gerl R, et al. Posterior capsule opacification after implantation of CeeOnEdge 911A, PhacoFlex SI-40NB, and AcrySof MA60BM lenses: one-year results of an intraindividual comparison multicenter study. J Cataract Refract Surg. 2004;30:978-985.

3. Buehl W, Menapace R, Findl O, et al. Long-term effect of optic edge design in a silicone intraocular lens on posterior capsule opacification. Am J Ophthalmol. 2007;143:913-919.

4. Iwase T, Nishi Y, Oveson BC, Jo YJ. Hydrophobic versus double-squareedged hydrophilic foldable acrylic intraocular lens: effect on posterior capsule opacification. J Cataract Refract Surg. 2011;37:1060-1068.

5. Bender LE, Nimsgern C, Jose R, et al. Effect of 1-piece and 3-piece AcrySof intraocular lenses on the development of posterior capsule opacification after cataract surgery. J Cataract Refract Surg. 2004;30:786-789.

6. Leydolt C, Davidovic S, Sacu S, et al. Long-term effect of 1-piece and 3-piece hydrophobic acrylic intraocular lens on posterior capsule opacification: a randomized trial. Ophthalmology. 2007;114:1663-1669.
7. Nishi Y, Rabsilber TM, Limberger IJ, Reuland AJ, Auffarth GU. Influence of 360-degree enhanced optic edge design of a hydrophilic acrylic intraocular lens on posterior capsule opacification. $J$ Cataract Refract Surg. 2007;33:227-231.

8. Findl O, Menapace R, Sacu S, Buehl W, Rainer G. Effect of optic material on posterior capsule opacification in intraocular lenses with sharp-edge optics: randomized clinical trial. Ophthalmology. 2005;112: $67-72$.

9. Hayashi K, Hayashi H. Influence on posterior capsule opacification and visual function of intraocular lens optic material. Am J Ophthalmol. 2007; 144:195-202.

10. Kugelberg M, Wejde G, Jayaram H, Zetterström C. Two-year follow-up of posterior capsule opacification after implantation of a hydrophilic or hydrophobic acrylic intraocular lens. Acta Ophthalmol. 2008;86:533-536.

11. Vasavada AR, Raj SM, Shah A, et al. Comparison of posterior capsule opacification with hydrophobic acrylic and hydrophilic acrylic intraocular lenses. J Cataract Refract Surg. 2011;37:1050-1059.

12. Vock L, Menapace R, Stifter E, et al. Posterior capsule opacification and neodymium:YAG laser capsulotomy rates with a round-edged silicone and a sharp-edged hydrophobic acrylic intraocular lens 10 years after surgery. J Cataract Refract Surg. 2009;35:459-465.

13. Vock L, Crnej A, Findl O, et al. Posterior capsule opacification in silicone and hydrophobic acrylic intraocular lenses with sharp-edge optics six years after surgery. Am J Ophthalmol. 2009;147:683-690.

14. Hirnschall N, Neumayer T, Georgopoulos M, Findl O. Effect of Nd:YAG capsulotomy on the morphology of surviving Elschnig pearls. Br J Ophthalmol. 2009;93:1643-1647.

15. Nishi O, Nishi K, Sakanishi K. Inhibition of migrating lens epithelial cells at the capsular bend created by the rectangular optic edge of a posterior chamber intraocular lens. Ophthalmic Surg Lasers. 1998;29: 587-594.

16. Nishi O, Nishi K, Akura J. Speed of capsular bend formation at the optic edge of acrylic, silicone, and poly(methyl methacrylate) lenses. $J$ Cataract Refract Surg. 2002;28:431-437.

17. Nishi O, Yamamoto N, Nishi K, Nishi Y. Contact inhibition of migrating lens epithelial cells at the capsular bend created by a sharp-edged intraocular lens after cataract surgery. J Cataract Refract Surg. 2007;33: $1065-1070$.

18. Rønbeck M, Kugelberg M. Posterior capsule opacification with 3 intraocular lenses: 12-year prospective study. J Cataract Refract Surg. 2014;40:70-76.

19. Nanavaty MA, Spalton DJ, Boyce J, et al. Edge profile of commercially available square-edged intraocular lenses. $J$ Cataract Refract Surg. 2008;34:677-686.

20. Werner L, Müller M, Tetz M. Evaluating and defining the sharpness of intraocular lenses: microedge structure of commercially available squareedged hydrophobic lenses. J Cataract Refract Surg. 2008;34:310-317.

21. Petternel V, Menapace R, Findl O, et al. Effect of optic edge design and haptic angulation on postoperative intraocular lens position change. J Cataract Refract Surg. 2004;30:52-57.
Clinical Ophthalmology

\section{Publish your work in this journal}

Clinical Ophthalmology is an international, peer-reviewed journal covering all subspecialties within ophthalmology. Key topics include: Optometry; Visual science; Pharmacology and drug therapy in eye diseases; Basic Sciences; Primary and Secondary eye care; Patient Safety and Quality of Care Improvements. This journal is indexed on Submit your manuscript here: http://www.dovepress.com/clinical-ophthalmology-journal

\section{Dovepress}

PubMed Central and CAS, and is the official journal of The Society of Clinical Ophthalmology (SCO). The manuscript management system is completely online and includes a very quick and fair peer-review system, which is all easy to use. Visit http://www.dovepress.com/ testimonials.php to read real quotes from published authors. 